\title{
Pancreatic Fibrosis Correlates with Exocrine Pancreatic Insufficiency after Pancreatoduodenectomy
}

\author{
T.C.K. $\operatorname{Tran}^{\mathrm{a}}$ G. van 't Hof ${ }^{\mathrm{a}} \quad$ G. Kazemier ${ }^{\mathrm{a}}$ W.C. Hop ${ }^{\mathrm{b}}$ C. Pek ${ }^{\mathrm{a}}$ \\ A.W. van Toorenenbergen ${ }^{c} \quad H$. van Dekken $^{d}$ C.H.J. van Eijck ${ }^{a}$ \\ Departments of a Surgery, ${ }^{\mathrm{b}}$ Biostatistics, ${ }^{\mathrm{c} C l i n i c a l}$ Chemistry and ${ }^{\mathrm{d}}$ Pathology, Erasmus Medical Center, \\ Rotterdam, The Netherlands
}

\section{Key Words}

Exocrine-endocrine pancreatic function •

Pancreatoduodenectomy $\cdot$ Pancreatic fibrosis

\begin{abstract}
Background: Obstruction of the pancreatic duct can lead to pancreatic fibrosis. We investigated the correlation between the extent of pancreatic fibrosis and the postoperative exocrine and endocrine pancreatic function. Methods: Fifty-five patients who were treated for pancreatic and periampullary carcinoma and 19 patients with chronic pancreatitis were evaluated. Exocrine pancreatic function was evaluated by fecal elastase-1 test, while endocrine pancreatic function was assessed by plasma glucose level. The extent of fibrosis, duct dilation and endocrine tissue loss was examined histopathologically. Results: A strong correlation was found between pancreatic fibrosis and elastase- 1 level less than $100 \mu \mathrm{g} / \mathrm{g}$ $(p<0.0001)$, reflecting severe exocrine pancreatic insufficiency. A strong correlation was found between pancreatic fibrosis and endocrine tissue loss $(p<0.0001)$. Neither pancreatic fibrosis nor endocrine tissue loss were correlated with the development of postoperative diabetes mellitus. Duct dilation alone was neither correlated with exocrine nor with endocrine function loss. Conclusion: The majority of
\end{abstract}

patients develop severe exocrine pancreatic insufficiency after pancreatoduodenectomy. The extent of exocrine pancreatic insufficiency is strongly correlated with preoperative fibrosis. The loss of endocrine tissue does not correlate with postoperative diabetes mellitus. Preoperative dilation of the pancreatic duct per se does not predict exocrine or endocrine pancreatic insufficiency postoperatively.

Copyright $\odot 2008$ S. Karger AG, Basel

\section{Introduction}

Both pylorus-preserving pancreatoduodenectomy and the classic Whipple resection are nowadays standard procedures for various benign and malignant diseases in the periampullary region. The morbidity, mortality and long-term survival after resection have been reported to be comparable for both procedures [1-4].

Advances in operative techniques and improvements in perioperative management have led to an increasing number of long-term survivors after resection [5]. Therefore, their functional outcomes have attracted more attention. Exocrine and endocrine pancreatic functions seem to be affected by factors such as the type of pancreatoenterostomy, the preoperative condition of the pan-

\section{KARGER}

Fax +4161306 1234 E-Mail karger@karger.ch www.karger.com
(ㄷ) 2008 S. Karger AG, Basel

0253-4886/08/0254-0311\$24.50/0

Accessible online at:

www.karger.com/dsu
T.C.K. Tran

Department of Surgery

Erasmus Medical Center, 'sGravendijkwal 230

NL-3015 CE Rotterdam (The Netherlands)

Tel. +31 10463 3854, Fax +31 10463 3350, E-Mail t.tran@erasmusmc.nl 
creas and the volume of the resected pancreas. However, the real pathogenesis behind pancreatic function loss remains unclear. From a clinical point of view, the late postoperative period is frequently characterized by various gastrointestinal problems, such as weight loss, malabsorption of essential nutrients (for example, fat-soluble vitamins) and steatorrhea, due to malfunctioning of the pancreatic remnant. Furthermore, we observed an interesting fact that even in patients with a relatively normal pancreatic remnant, exocrine insufficiency occurs at the time of operation. Moreover, a substantial part of the patients develop diabetes mellitus after pancreatoduodenectomy. Fibrosis of the parenchyma of the pancreas has never been investigated before as a factor contributing to the malfunction of the pancreatic remnant.

Therefore, we hypothesized that fibrosis of the pancreatic remnant secondary to chronic pancreatic duct obstruction might contribute to these functional changes of the pancreas.

The aim of this study was to assess the correlation between the preoperative changes of the pancreas parenchyma (as reflected by the dilation of the pancreatic duct and the extent of fibrosis at the plane of transection) and the postoperative exocrine and endocrine function at least 6 months after pancreatoduodenectomy.

\section{Patients and Methods}

\section{Clinical Characteristics}

In 2006, a nonconsecutive series of 55 patients, who had undergone pancreatoduodenectomy for either pancreatic or periampullary cancer at the Erasmus Medical Center in Rotterdam (The Netherlands) between 2001 and 2005, were evaluated for this clinical study. Thirty-two patients had been treated for pancreatic cancer and 23 for periampullary cancer. Periampullary cancer was defined as cancer of the papilla vateri, distal bile duct cancer or periampullary duodenal cancer; pancreatic cancer was defined as cancer elsewhere in the pancreatic parenchyma. In addition, 19 patients with chronic pancreatitis who underwent pancreatoduodenectomy during the same period were studied.

Patients were evaluated in the outpatient clinic, where they were seen as a consecutive group for follow-up. Patients had to be at least 6 months after operation without signs of tumor recurrence and their resection specimen had to be available for careful examination.

There were 45 men and 29 women. The mean age of these patients was 58.5 years (range $20-83$ ).

\section{Surgery}

After exclusion of distant metastasis and local irresectability, all patients underwent pancreatoduodenectomy. Twenty-six patients had a classical Kausch-Whipple resection, whereas 48 patients underwent pylorus-preserving pancreatoduodenectomy.
End-to-side double-layer duct-to-mucosa pancreatojejunostomy was made according to the technique described by Cattell [6]. Subsequently, single-layer end-to-side hepaticojejunostomy was performed. Finally antecolic end-to-side anastomosis was made between either the proximal duodenum or the gastric remnant and the proximal jejunum.

\section{Exocrine Function Assessment}

To assess exocrine pancreatic function, the fecal elastase- 1 test was used. Two feces samples were collected from each patient at least 6 months postoperatively. In 20 patients, preoperative elastase- 1 concentration was also available. The elastase-1 concentration was measured with a commercially available ELISA kit (Schebo Biotech AG, Giessen, Germany). Enzyme replacement therapy was continued during the test period, since this does not affect the test results [7].

Pancreatic function was considered normal when fecal elastase- 1 concentration exceeded $200 \mu \mathrm{g} / \mathrm{g}$ feces, moderately insufficient when fecal elastase- 1 concentration was between 100 and $200 \mu \mathrm{g} / \mathrm{g}$ feces and severely insufficient when elastase- 1 concentration was less than $100 \mu \mathrm{g} / \mathrm{g}$ feces.

\section{Endocrine Function Assessment}

Before surgery, apart from a casual glucose and hemoglobin glucose level determination, patients were asked whether they suffered from diabetes mellitus, polydipsia or polyuria and whether they used insulin or oral antidiabetic medication. During follow-up, casual glucose levels were measured frequently and patients were asked the same questions.

\section{Histology}

The use of a semiquantitative method (the subjective quantification of an experienced individual pathologist) in the assessment of histological changes of parenchyma, such as fibrosis, is considered accurate.

In order to score the atrophy of the pancreas, an experienced gastrointestinal pathologist (H.v.D.) examined the plane of resection through the pancreas. Serial cross-sections of the plane of resection were fixed in $20 \%$ neutral phosphate-buffered formalin for light microscopy. Paraffin sections were stained with hematoxylin and eosin. The extent of fibrosis and remaining functional exocrine tissue were assessed using a semiquantitative measurement method with 20 -fold enlargement for light microscopy. Abnormalities were classified as mild or not affected if less than $25 \%$ fibrosis was observed, moderate if there was $25-75 \%$ and severe if more than $75 \%$ fibrosis was present (fig. 1). Furthermore, the extent of dilation of the pancreatic duct was assessed. Dilation was defined as a duct diameter of more than $2 \mathrm{~mm}$. In patients with missing histological duct samples, operation reports and radiological data were screened for signs of duct dilation.

Endocrine tissue loss was determined in the plane of resection through the pancreas. Because of the more spread distribution of islands of Langerhans in the pancreatic corpus/tail, the presence of endocrine tissue was scored in only 2 categories semiquantitatively, that is, as mild when the estimated loss of endocrine tissue in the parenchyma was less than $50 \%$ compared with a normal pancreas parenchyma or as severe when the estimated loss of endocrine tissue was more than $50 \%$. 

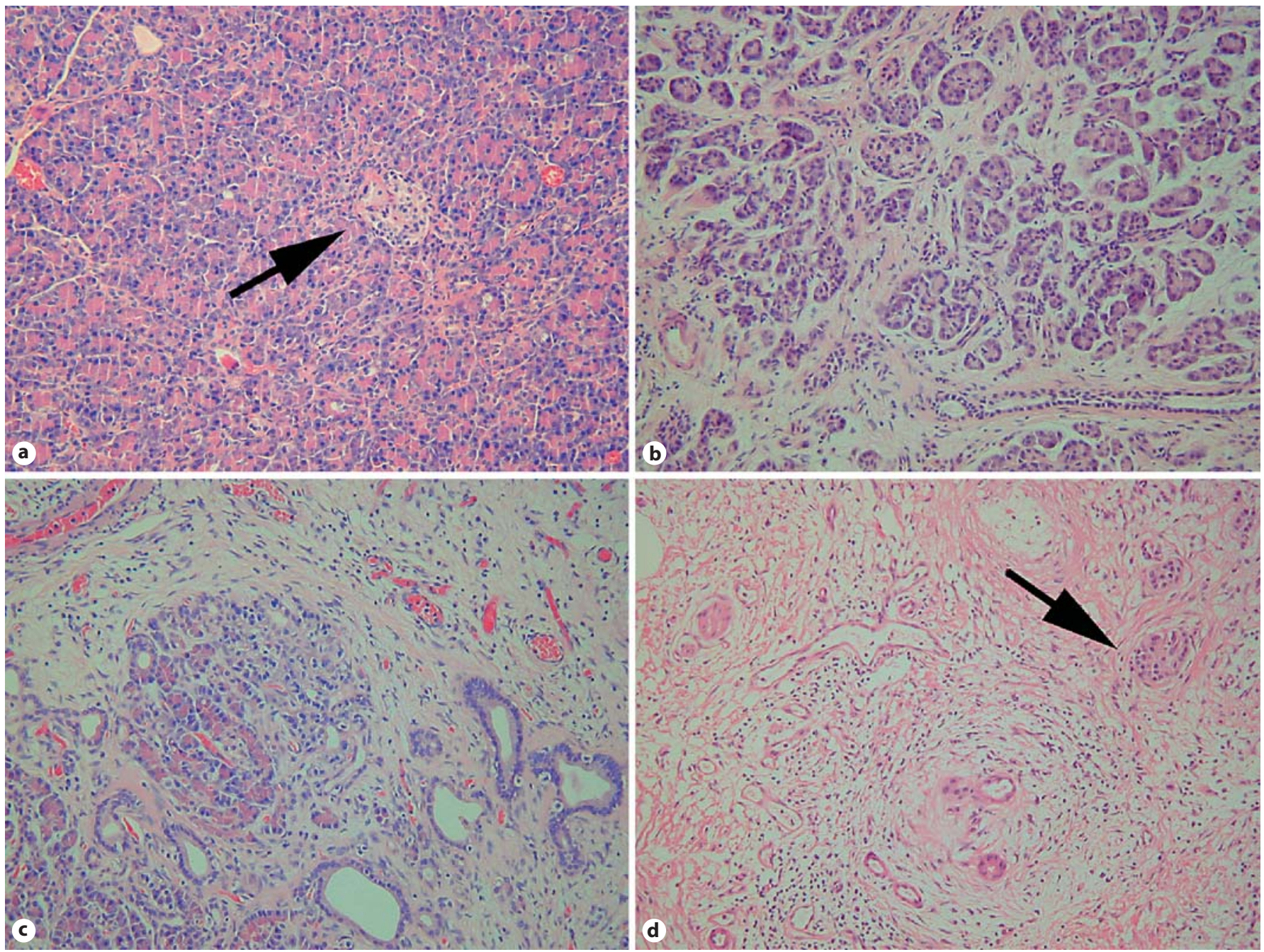

Fig. 1. Histopathological classification of pancreatic fibrosis. a Normal pancreatic parenchyma with normal distribution of exocrine and endocrine tissue (arrow indicates Langerhans islet). b Mild fibrosis. c Moderate fibrosis. d Severe fibrosis (arrow indicates Langerhans islet).

\section{Statistics}

Data were analyzed using SPSS ${ }^{\circledR}$ version 11.0 (SPSS Inc., Chicago, Ill., USA). The Mann-Whitney U test was performed for assessing the study population means. Spearman's rank test was used to determine correlations. The one-way ANOVA test was used to compare means of different groups, post hoc tested with the Bonferroni test. Test results were considered to denote statistical significance if $\mathrm{p}<0.05$.

\section{Results}

\section{Elastase-1}

Of the 74 patients, 56 (76\%) showed fecal elastase-1 levels less than $100 \mu \mathrm{g} / \mathrm{g}$, indicating severe pancreatic in- sufficiency. Nine patients had elastase-1 levels between 100 and $200 \mu \mathrm{g} / \mathrm{g}$, indicating mild insufficiency, and only 9 patients had elastase levels above $200 \mu \mathrm{g} / \mathrm{g}$, which indicates a normally functioning remnant.

There was no significant difference in distribution of exocrine insufficiency in the 3 distinct groups as identified by underlying disease: severe insufficiency was found in $28 / 32$ patients $(88 \%)$ with pancreatic cancer, in $13 / 23$ patients (57\%) with periampullary cancer and in $15 / 19$ patients $(79 \%)$ with chronic pancreatitis.

In the 20 patients in whom both pre- and postoperative elastase-1 levels were available, there was a significant decline postoperatively ( $\mathrm{p}<0.02$; fig. 2 ). 


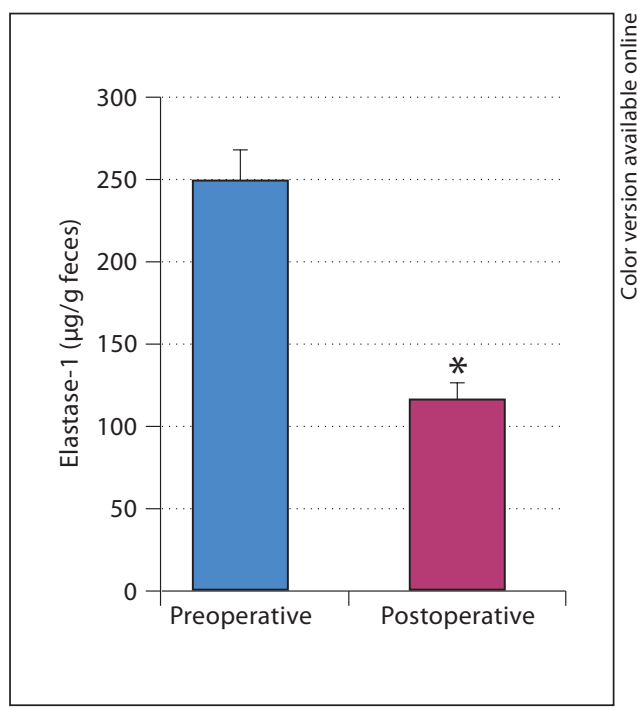

Fig. 2. Preoperative and postoperative elastase- 1 concentration in 20 patients who underwent pancreatoduodenectomy. ${ }^{*} \mathrm{p}=0.02$.

\section{Fibrosis}

In 7 patients, no histological examination could be performed because of missing samples. Of the remaining 67 patients, 33 had mild, 15 moderate and 19 severe fibrosis. The distribution of the extent of fibrosis between the groups with different underlying disease is shown in table 1; there was no significant difference between the groups $(\mathrm{p}=0.08)$. A strong inverse correlation was observed between the extent of fibrosis and the level of elastase-1 in the fecal samples, both reflecting exocrine tissue loss ( $\mathrm{p}<0.0001$; fig. 3$)$.

\section{Duct Dilation}

In 2 patients, no data could be retrieved to assess pancreatic duct diameter. The extent of pancreatic duct dilation in the groups with different underlying diseases is outlined in table 1; no significant difference was found between the 3 groups $(\mathrm{p}=0.162)$. There was no (inversed) correlation between a dilated pancreatic duct and elastase-1 levels in the feces $(\mathrm{p}=0.599)$ or extent of fibrosis in the resection plane $(\mathrm{p}=0.464)$.

\section{Endocrine Tissue}

The loss of endocrine tissue in the resection plane could not be assessed in 7 patients because of missing samples. The results of endocrine tissue assessment are shown in table 1. Again, there were no significant differences between the groups $(p<0.838)$. A strong correlation existed between endocrine tissue loss and the extent

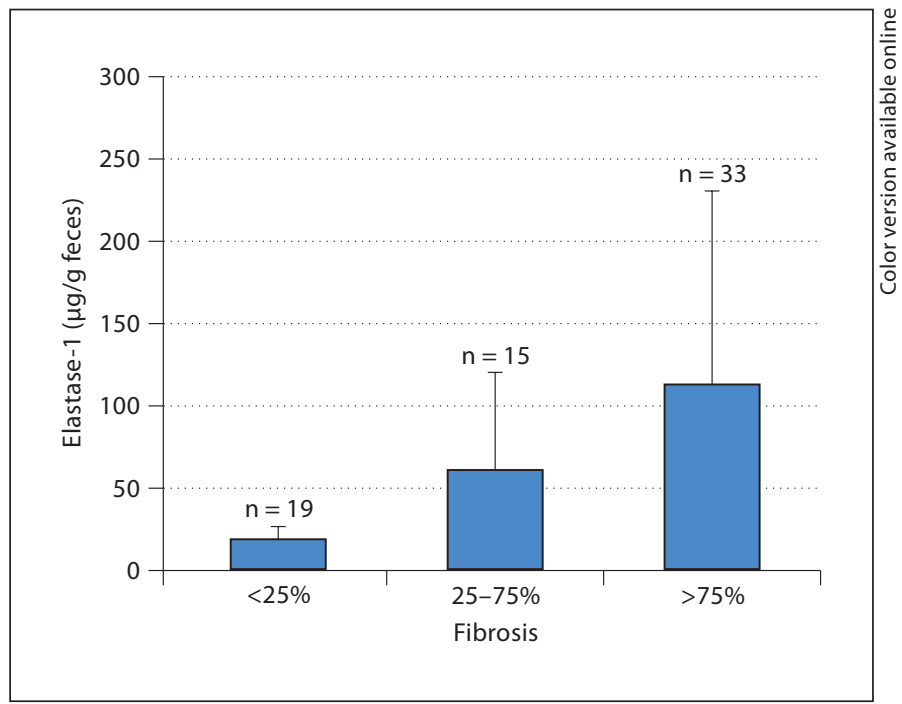

Fig. 3. Inversed correlation between the extent of fibrosis and elastase-1 level. $\mathrm{p}<0.0001$.

of fibrosis $(\mathrm{p}<0.0001)$. No correlation existed between endocrine tissue loss and pancreatic duct dilation ( $\mathrm{p}=$ $0.735)$.

\section{Diabetes Mellitus}

There were no missing samples. Sixty-four patients did not have diabetes before the operation. Prior to surgery, 6 patients were already diagnosed as having insulin-dependent diabetes and 4 patients were on oral antidiabetic medication. Overall, 19 patients (26\%) developed diabetes after the operation (13 insulin-dependent diabetes, 6 noninsulin-dependent diabetes). Neither for pancreatic duct dilation ( $\mathrm{p}=0.543)$ nor for endocrine tissue loss $(\mathrm{p}=0.521)$ could a correlation be identified with postoperative diabetes (with or without preoperative diabetes).

\section{Discussion}

This study focuses on the postoperative pancreatic function and its relation with preoperative loss of exocrine and endocrine pancreatic tissue (fibrosis) and a dilated pancreatic duct. Pancreatic function can be altered during the course of chronic pancreatitis. The main reasons for the development of insufficiency are fibrosis and loss of functional tissue. In pancreatic cancer, especially the periampullary cancers, the destruction by cancer tissue can be comprehended, but the remaining tissue is supposed to be sufficient and normal. 
Table 1. Distribution of histological and hormonal changes in patients with pancreatic carcinoma, periampullary carcinoma and chronic pancreatitis

\begin{tabular}{|c|c|c|c|c|c|}
\hline Fibrosis & Unknown & $\begin{array}{l}\text { Mild } \\
(<25 \%)\end{array}$ & $\begin{array}{l}\text { Moderate } \\
(25-75 \%)\end{array}$ & $\begin{array}{l}\text { Severe } \\
(>75 \%)\end{array}$ & Total \\
\hline Pancreatic carcinoma & 3 & 12 & 5 & 12 & 32 \\
\hline Periampullary carcinoma & 4 & 15 & 4 & 0 & 23 \\
\hline Chronic pancreatitis & 0 & 6 & 6 & 7 & 19 \\
\hline Total & 7 & 33 & 15 & 19 & 74 \\
\hline Pancreatic duct dilation & Unknown & \multicolumn{3}{|r|}{ Duct dilation } & Total \\
\hline Pancreatic carcinoma & 0 & 4 & \multicolumn{2}{|r|}{28} & 32 \\
\hline Periampullary carcinoma & 1 & 4 & \multicolumn{2}{|c|}{18} & 23 \\
\hline Chronic pancreatitis & 1 & 7 & \multicolumn{2}{|c|}{11} & 19 \\
\hline Total & 2 & 15 & \multicolumn{2}{|c|}{57} & 74 \\
\hline $\begin{array}{l}\text { Endocrine tissue } \\
\text { (\% Langerhans islets) }\end{array}$ & Unknown & Low $(0-50 \%)$ & \multicolumn{2}{|r|}{ High (50-100\%) } & Total \\
\hline Pancreatic carcinoma & 3 & 14 & \multicolumn{2}{|r|}{15} & 32 \\
\hline Periampullary carcinoma & 4 & 1 & \multicolumn{2}{|r|}{18} & 23 \\
\hline Chronic pancreatitis & 0 & 9 & \multicolumn{2}{|r|}{10} & 19 \\
\hline Total & 7 & 24 & \multicolumn{2}{|c|}{43} & 74 \\
\hline Diabetes mellitus & None & Preoperative & \multicolumn{2}{|r|}{ Postoperative } & Total \\
\hline Pancreatic carcinoma & 20 & 5 & \multicolumn{2}{|r|}{7} & 32 \\
\hline Periampullary carcinoma & 14 & 3 & \multicolumn{2}{|r|}{6} & 23 \\
\hline Chronic pancreatitis & 11 & 2 & \multicolumn{2}{|r|}{6} & 19 \\
\hline Total & 45 & 10 & \multicolumn{2}{|r|}{19} & 74 \\
\hline
\end{tabular}

The majority of patients showed postoperative fecal elastase-1 levels lower than $100 \mu \mathrm{g} / \mathrm{g}$, indicating severe exocrine pancreatic insufficiency. Pancreatoduodenectomy is associated with exocrine and endocrine alterations [8-11]. During follow-up, patients frequently report difficulties with food intake, periods of diarrhea, altered consistency of feces, steatorrhea and symptoms of malabsorption and subsequent malnutrition [12]. Huang et al. [13] reported a prevalence of 47 and 59\% for foul stool after pancreatoduodenectomy because of malignant or benign pathology respectively, as well as 41 and 39\% diabetes, respectively, in a population of 192 patients. In another study, exocrine insufficiency symptoms like gross steatorrhea increased from $17 \%$ before to $43 \%$ after surgery [14].

Exocrine insufficiency can be tested by direct or indirect function tests. The direct tests are more time-consuming, more expensive and unpleasant for the patients. Indirect tests, such as the fecal elastase-1 test, measure the consequences of pancreatic insufficiency and are more widely available.

Pancreatic Fibrosis and Exocrine Pancreatic Insufficiency
The elastase-1 test was used because of the good results obtained in previous studies in assessing moderate to severe exocrine dysfunction of the pancreas [7, 15-20]. This test has several advantages. First of all, the enzyme is stable during intestinal transport, secondly, elastase is concentrated in the feces, and finally, the enzyme is easily detected by means of an ELISA test.

Pancreatic atrophy and concomitant fibrosis are thought to be responsible for the loss of exocrine and endocrine function [21]. Occlusion of the pancreatic duct by tumor, by chronic inflammation coexisting with tumor or merely by chronic pancreatitis, causes fibrosis of the parenchyma [22-25]. In this study, a significant inversed correlation was found between the histopathological extent of fibrosis and the level of elastase- 1 test in the feces.

Tanaka et al. [24] reported an improvement of exocrine pancreatic function after 1 year compared with the test results within 2 months postoperatively. We did not analyze this phenomenon, since we only investigated patients more than 6 months postoperatively. In contrast to

Dig Surg 2008;25:311-318 
data from the literature, no inversed correlation was found between a dilated pancreatic duct and postoperative elastase-1 levels in the feces $(p=0.599)$. Dilation of the pancreatic duct was neither correlated with exocrine nor with endocrine tissue loss. Therefore, a dilated pancreatic duct may be a sign of serious disease, but not a parameter of tissue destruction. Sato et al. [23] mentioned a short-term postoperative exocrine impairment in patients with a preoperatively dilated pancreatic duct. Interestingly, a substantial number of patients in our study with a normal pancreatic duct at the time of operation and only mild fibrosis still developed a severe exocrine insufficiency postoperatively, which suggests an ongoing exocrine and endocrine tissue loss after pancreatoduodenectomy. Pancreatic atrophy, as assessed by subtracting the diameter of the pancreatic duct from the total gland thickness, has previously been shown to develop over time following pancreatoduodenectomy [26] and to correlate well with exocrine insufficiency. Partial or total obstruction of the anastomosis might explain this phenomenon in some of the patients. Even a duct-to-mucosa anastomosis (which we also performed in all patients) could not prevent the ongoing process of tissue destruction in that study. It has been suggested that a pancreatojejunostomy allows a better preservation of the pancreatic exocrine function than a pancreatogastrostomy, which may be explained at least partly by neutralization of pancreatic enzymatic secretions due to gastric acid.

In our study, a strong correlation existed between endocrine tissue loss and the extent of fibrosis, but there was no correlation between endocrine tissue loss and pancreatic duct dilation. Strikingly, neither pancreatic duct dilation nor endocrine tissue loss were correlated with postoperative diabetes mellitus. Since pancreatic fibrosis and exocrine tissue loss were studied 6 months before the clinical endocrine and exocrine study, the observation that endocrine tissue loss is not correlated with diabetes mellitus could be explained by the persistence of endocrine tissue loss after the operation. This could also explain the fact that not all patients known with diabetes mellitus after 6 months were diabetic directly postoperatively.

In a recent review, $70 \%$ of patients with pancreatic carcinoma had an impaired glucose tolerance test or frank diabetes preoperatively [27]. Some authors suggest that diabetes may be an early manifestation of pancreatic malignancies [10, 28]. Jang et al. [29] reported an onset of diabetes mellitus in $44 \%$ of patients after pancreatoduodenectomy with pancreatojejunostomy and even in $75 \%$ after pancreatoduodenectomy with pancreatogastrostomy. Sakorafas et al. [14] reported an increase in diabetes from $8 \%$ before to $48 \%$ after pancreatoduodenectomy for chronic pancreatitis.

In pancreatic head resection, $30-50 \%$ of the pancreatic parenchyma is involved and thus some degree of pancreatic insufficiency is induced [30,31]. Taking into account that most of the Langerhans islets are located in the tail of the pancreas, which is left in situ during pancreatoduodenectomy [26], the frequent postoperative onset of diabetes is less easy to explain. It has been suggested that other mechanisms are involved, such as an ongoing atrophy of the pancreatic parenchyma with impairment of the function of the islets of Langerhans. The loss of insulin-secreting capacity was clearly shown in experimental data with dogs after pancreatic duct obstruction [25]. Clinical data from our group showed that iatrogenic pancreatic duct occlusion after pancreatoduodenectomy leads to a significantly higher risk of endocrine insufficiency [32].

More than one quarter of the patients developed diabetes after the operation, while 1 of 7 had diabetes already preoperatively. The decline of glucose tolerance after pancreatoduodenectomy seems to be associated with a low reserve of endocrine function rather than with the choice of a specific anastomosis (pancreaticojejunostomy or pancreaticogastrostomy) with its related complications [33].

Our study has several limitations. Since the study population consisted of a nonconsecutive series of patients who were enrolled over a relatively long study period, an unintended patient selection bias might have played a role. However, as with other studies of pancreatic cancer, many patients died before enrollment, developed recurrent disease or were lost to follow-up. As the aim of this study was to assess the correlation between the preoperative changes of the pancreas parenchyma and the postoperative exocrine and endocrine function at least 6 months after pancreatoduodenectomy, we did not mean to measure the elastase- 1 concentration preoperatively. The results of elastase- 1 concentration were notably abnormal during the study period and for this reason we decided to measure the elastase- 1 concentration also in the preoperative phase in order to compare. This could be obtained from a small number of patients $(n=20)$. Another criticism might be the relatively small number of patients in this study, which induces the risk of type 2 statistical errors. The study objectives were merely aimed at the clinical signs and feasibility of quantification of a histological observation. Since the results were obvious, we concluded that it was not necessary to extend the number of patients. 
Furthermore, a later time point would have given more information about the course of the exocrine and endocrine insufficiency. Because the long-term survivors after a pancreatoduodenectomy do not seem to improve over years, the quality of life aspects become more important and therefore improvements in the clinical conditions must be pursued.

Finally, the semiquantitative histopathological analysis might be a relatively inaccurate method to judge the loss of exocrine and endocrine tissue.

In conclusion, after pancreatoduodenectomy, the extent of exocrine pancreatic insufficiency is strongly correlated with preoperative fibrosis reflecting the preoperative loss of functional pancreatic tissue. However, the loss of endocrine tissue does not correlate with postoperative diabetes mellitus. Preoperative dilation of the pancreatic duct per se does not predict exocrine or endocrine pancreatic insufficiency postoperatively.

The high frequency of both exocrine and endocrine insufficiency after pancreatoduodenectomy warrants careful enzymatic supplementation and hormonal regulation during postoperative follow-up.

\section{Acknowledgement}

The authors would like to thank professor J.J.B. van Lanschot, $\mathrm{MD}$, for his advice and critical review of the manuscript.

\section{References}

1 Klinkenbijl JH, Jeekel J, Sahmoud T, van Pel $\mathrm{R}$, Couvreur ML, Veenhof $\mathrm{CH}$, Arnaud JP, Gonzalez DG, de Wit LT, Hennipman A, Wils J: Adjuvant radiotherapy and 5-fluorouracil after curative resection of cancer of the pancreas and periampullary region: phase III trial of the EORTC gastrointestinal tract cancer cooperative group. Ann Surg 1999;230:776-782.

2 Lin PW, Lin YJ: Prospective randomized comparison between pylorus-preserving and standard pancreaticoduodenectomy. Br J Surg 1999;86:603-607.

- 3 Seiler CA, Wagner M, Sadowski C, Kulli C, Buchler MW: Randomized prospective trial of pylorus-preserving vs. classic duodenopancreatectomy (Whipple procedure): initial clinical results. J Gastrointest Surg 2000; 4:443-452.

4 Tran KT, Smeenk HG, van Eijck CH, Kazemier G, Hop WC, Greve JW, Terpstra OT, Zijlstra JA, Klinkert P, Jeekel H: Pylorus preserving pancreaticoduodenectomy versus standard Whipple procedure: a prospective, randomized, multicenter analysis of 170 patients with pancreatic and periampullary tumors. Ann Surg 2004;240:738-745.

5 Kennedy EP, Yeo CJ: Pancreaticoduodenectomy with extended retroperitoneal lymphadenectomy for periampullary adenocarcinoma. Surg Oncol Clin N Am 2007; 16: $157-176$.

6 Cattell RB: A technic of exposure in secondary operations on the biliary tract. Surg Clin North Am 1950;30:867-872.

7 Dominguez-Munoz JE, Hieronymus C, Sauerbruch T, Malfertheiner P: Fecal elastase test: evaluation of a new noninvasive pancreatic function test. Am J Gastroenterol 1995; 90:1834-1837.
8 McLeod RS, Taylor BR, O'Connor BI, Greenberg GR, Jeejeebhoy KN, Royall D, Langer B: Quality of life, nutritional status, and gastrointestinal hormone profile following the Whipple procedure. Am J Surg 1995;169: 179-185.

-9 Melvin WS, Buekers KS, Muscarella P, Johnson JA, Schirmer WJ, Ellison EC: Outcome analysis of long-term survivors following pancreaticoduodenectomy. J Gastrointest Surg 1998;2:72-78.

10 Pfeffer F, Nauck MA, Benz S, Hopt UT: Secondary diabetes in pancreatic carcinoma and after pancreatectomy: pathophysiology, therapeutic peculiarities and prognosis. Z Gastroenterol 1999(suppl 1):10-14.

-11 Rumpf KD, Antonschmidt J, Dartan C, Zick $\mathrm{R}$, Canzler H: Function of the residual pancreas following partial duodeno-pancreatectomy. Chir Forum Exp Klin Forsch 1979; 293-297.

12 Armstrong T, Walters E, Varshney S, Johnson CD: Deficiencies of micronutrients, altered bowel function, and quality of life during late follow-up after pancreaticoduodenectomy for malignancy. Pancreatology 2002;2:528-534.

13 Huang JJ, Yeo CJ, Sohn TA, Lillemoe KD, Sauter PK, Coleman J, Hruban RH, Cameron JL: Quality of life and outcomes after pancreaticoduodenectomy. Ann Surg 2000;231: 890-898.

14 Sakorafas GH, Farnell MB, Farley DR, Rowland CM, Sarr MG: Long-term results after surgery for chronic pancreatitis. Int J Pancreatol 2000;27:131-142.
5 Cavalot F, Bonomo K, Perna P, Bacillo E, Salacone P, Gallo M, Mattiello L, Trovati M, Gaia E: Pancreatic elastase-1 in stools, a marker of exocrine pancreas function, correlates with both residual beta-cell secretion and metabolic control in type 1 diabetic subjects. Diabetes Care 2004;27:2052-2054.

16 Gullo L, Ventrucci M, Tomassetti P, Migliori M, Pezzilli R: Fecal elastase 1 determination in chronic pancreatitis. Dig Dis Sci 1999;44: 210-213.

17 Lankisch PG, Schmidt I, Konig H, Lehnick D, Knollmann R, Lohr M, Liebe S: Faecal elastase 1: not helpful in diagnosing chronic pancreatitis associated with mild to moderate exocrine pancreatic insufficiency. Gut 1998;42:551-554.

18 Loser C, Mollgaard A, Folsch UR: Faecal elastase 1: a novel, highly sensitive, and specific tubeless pancreatic function test. Gut 1996;39:580-586.

19 Luth S, Teyssen S, Forssmann K, Kolbel C, Krummenauer F, Singer MV: Fecal elastase1 determination: 'gold standard' of indirect pancreatic function tests? Scand J Gastroenterol 2001;36:1092-1099.

20 Stein J, Jung M, Sziegoleit A, Zeuzem S, Caspary WF, Lembcke B: Immunoreactive elastase I: clinical evaluation of a new noninvasive test of pancreatic function. Clin Chem 1996;42:222-226

21 Ghaneh P, Neoptolemos JP: Exocrine pancreatic function following pancreatectomy. Ann N Y Acad Sci 1999;880:308-318.

22 Ohshio G, Tanaka T, Imamura T, Okada N, Yoshitomi S, Suwa H, Hosotani R, Imamura $\mathrm{M}$ : Exocrine pancreatic function in the early period after pancreatoduodenectomy and effects of preoperative pancreatic duct obstruction. Dig Dis Sci 1996;41:1947-1952. 
23 Sato N, Yamaguchi K, Yokohata K, Shimizu S, Morisaki T, Chijiiwa K, Tanaka M: Shortterm and long-term pancreatic exocrine and endocrine functions after pancreatectomy. Dig Dis Sci 1998;43:2616-2621.

24 Tanaka T, Ichiba Y, Fujii Y, Kodama O, Dohi $\mathrm{K}$ : Clinical and experimental study of pancreatic exocrine function after pancreaticoduodenectomy for periampullary carcinoma. Surg Gynecol Obstet 1988;166:200-205.

-25 van der Burg MP, Gooszen HG, Guicherit OR, Jansen JB, Frolich M, van Haastert FA, Lamers CB: Contribution of partial pancreatectomy, systemic hormone delivery, and duct obliteration to glucose regulation in canine pancreas. Importance in pancreas transplantation. Diabetes 1989;38:10821089.
26 Lemaire E, O’Toole D, Sauvanet A, Hammel P, Belghiti J, Ruszniewski P: Functional and morphological changes in the pancreatic remnant following pancreaticoduodenectomy with pancreaticogastric anastomosis. $\mathrm{Br}$ J Surg 2000;87:434-438.

27 Saruc M, Pour PM: Diabetes and its relationship to pancreatic carcinoma. Pancreas 2003; 26:381-387.

28 Duron F, Duron JJ: Pancreatectomy and diabetes. Ann Chir 1999;53:406-411.

29 Jang JY, Kim SW, Park SJ, Park YH: Comparison of the functional outcome after pylorus-preserving pancreatoduodenectomy: pancreatogastrostomy and pancreatojejunostomy. World J Surg 2002;26:366-371.

30 Kendall DM, Sutherland DE, Goetz FC, Najarian JS: Metabolic effect of hemipancreatectomy in donors: preoperative prediction of postoperative oral glucose tolerance. Diabetes 1989;38(suppl 1):101-103.
31 Witzigmann H, Max D, Uhlmann D, Geissler F, Schwarz R, Ludwig S, Lohmann T, Caca K, Keim V, Tannapfel A, Hauss J: Outcome after duodenum-preserving pancreatic head resection is improved compared with classic Whipple procedure in the treatment of chronic pancreatitis. Surgery 2003;134:5362.

>32 Tran K, Van EC, Di C, V, Hop WC, Zerbi A, Balzano G, Jeekel H: Occlusion of the pancreatic duct versus pancreaticojejunostomy: a prospective randomized trial. Ann Surg 2002;236:422-428.

33 Ishikawa O, Ohigashi $\mathrm{H}$, Eguchi H, Yokoyama S, Yamada T, Takachi K, Miyashiro I, Murata K, Doki Y, Sasaki Y, Imaoka S: Longterm follow-up of glucose tolerance function after pancreaticoduodenectomy: comparison between pancreaticogastrostomy and pancreaticojejunostomy. Surgery 2004;136: 617-623. 